Article

\title{
Between the Art Canon and the Margins: Historicizing Technology-Reliant Art via Curatorial Practice
}

\author{
Elena Papadaki
}

School of Design, University of Greenwich, London SE10 9BD, UK; e.papadaki@gre.ac.uk

Received: 10 July 2019; Accepted: 5 September 2019; Published: 18 September 2019

\begin{abstract}
This article explores curatorial practice that has technology-reliant works at its epicentre, arguing that for an efficient methodology to historicize the latter there needs to be a reconfiguration of the curatorial scope and a holistic approach to viewing and documenting exhibitions. Based on theoretical research and install decisions of recent years, the ways in which curatorial practice can be reconfigured within the art canon to inform art history, as well as to accommodate developments in exhibition practices are examined.
\end{abstract}

Keywords: curatorial practice; technology-reliant works; digital arts; exhibition histories; exhibition documentation

\section{Introduction}

Contemporary curatorial practice, especially when technology-reliant works are at its epicentre, seems to be balancing between two worlds. On one hand, there is an attempt for the inclusion of the works in the art history curriculum whilst on the other, the works themselves (especially as technology advances and more ways to exhibit outside the institutional framework become possible) find ways of expression that excludes them even further from a canonical exhibition framework and documentation.

The terminology itself seems to be contributing to this exclusion, as it often creates much confusion and disagreement. There is a plethora of terms that have been used throughout the years to define works that employ technology as part of their creation and/or final exhibited output: new media art, time-based media, video art, digital art, interactive art, ubiquitous gaming, VR installation, locative media, virtual art, projected image, screen-reliant work, to mention but a few. ${ }^{1}$ In the present case, technology-reliant is chosen as it remains open to the medium that creates/emits the exhibited output and to the fact that other media ('old' and 'new') and/or objects might be part of it. Although this is still an arbitrary term, it nevertheless serves the purposes of the present article.

In addition, another central issue when addressing technology-reliant art is the (often unfortunate) application of judgments of taste and quality that were created with a static object in mind (Graham and Cook 2010). In this context, the curatorial tendency to create content instead of context (ibid.) is often highlighted as a 'glitch' in the curatorial process. The qualities that technology-reliant art presents and its differentiation from static forms create a new set of rules for exhibition practices, as there is not always a 'pre-made' work of specific dimensions available to present in a pre-set venue,

1 Grau (2003, pp. xi, 4) Virtual Art-From Illusion to Immersion provides a useful mapping of this terrain, focusing on computer-simulated virtual environments and a genealogy of old and new media of illusion. Graham and Cook (2010), Mondloch (2010), Kholeif (2018), Shanken (2010), Meigh-Andrews (2006), and Trodd (2011) have equally chose one specific term as a consistent point of reference (whilst acknowledging the problematics of this definition), explaining how its characteristics represented the respective objects of study and research interests. For an analysis of the 'question of definition', see also Papadaki () Curating Screens-Art, Performance, and Public Spaces (doctoral thesis). 
while a dynamic exhibit that is potentially variable, interactive and experimental is possible. Along the same line, exhibitions that focus on both 'old' and 'new' technology-reliant art (such as the recent "Electronic Superhighway (2016-1966)" exhibition at Whitechapel Gallery in London) may present, history-wise, an unbalanced installation view. Most importantly, the possibilities offered by technology often take the 'artworks' out of the institutional walls and into public spaces, where they might serve specific and ephemeral purposes. In short, the set of criteria based on which the aforementioned works are assessed are by nature incompatible with canonical standards of historicization.

At the same time, technology itself is increasingly embedded within both exhibition practices and the creation of the works themselves, thus creating new relations between creators, curators, and visitors (who often double as participants in the creation of the work). Recent years have seen the rise of immersive technologies in museums, fairs, and festivals, whilst the free use of VR headsets, smartphones and apps has come to constitute common museological practice. Immersive technologies are not only used as an 'added bonus' to exhibitions but gradually become the exhibit. The inauguration of the first all-digital art museum (MORI building Digital Art Museum, Tokyo) in June 2018 reveals a 100,000 square foot space that functions merely as a shell for the interactive projections throughout it (Figure 1). TeamLab, the artist collective of 'ultratechnologists' (as they call themselves) behind the project, insist on the existence of physical spaces to host their art whilst promoting the idea that each exhibition moment is fluid and regulated by the visitors populating the space and interacting with the projected works. In situations like this, where an artist or an artist collective create a series of works that are meant to be seen as one entity and whose functioning and aesthetics are dependant on interaction with the public (as in the case of TeamLab and the Digital Art Museum above or, to mention but one example of a highly established new media artist within a western framework, the touring exhibitions for public spaces devised by Rafael Lozano-Hemmer), there is an additional challenge when attempting to place them within the art history canon. How are these exhibitions/works recorded and how are they included within this very canon?

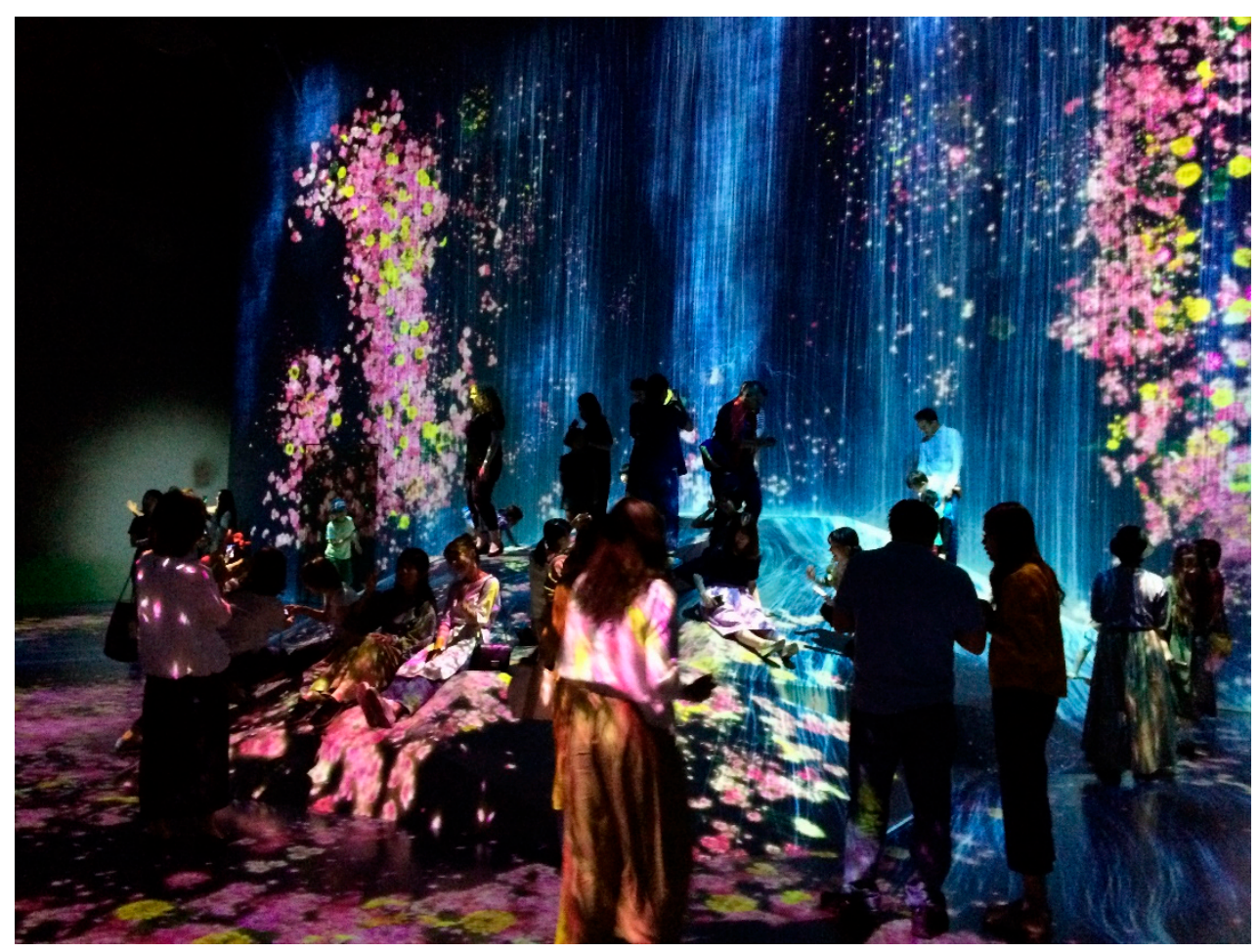

Figure 1. TeamLab. MORI building Digital Art Museum (2018), author's photo.

With these parameters in mind, how does one historicize when "dealing with live and changing things" and "emerging forms or things not yet named and categorized" (Cook 2014, p. 203)? Within 
the sphere of new technologies being constantly embedded into forms of art, it is true that one might feel that there are too many factors to consider, some of which (the technology itself, for instance) are probably outside our realm of understanding as far as their respective functions are concerned. In this context, it is not merely the change of point of view that is required in order for technology-reliant art to successfully enter the art historical canon, but a shift towards a more holistic approach when viewing, documenting and assessing exhibitions and the works that the latter are composed of. In the following sections, I will examine the role of curatorial practice in this process, via an examination of recent exhibitions that focused on the historicization of technology-reliant works and display issues that arose and affected both the visitors' experience and the overall reception of the exhibition rationale. In this way, I hope to demonstrate that a different set of rules applies to curatorial practices that engage with technology-reliant works and to suggest that audiovisual documentation constitutes an essential methodological tool towards the accurate historicization of the works in question.

\section{Expanding the Canon}

It has been argued that during the 1960s, exhibition discourse moved away from an analysis of the work of art as an autonomous object and started focusing on the contextual characteristics and the space of an exhibition (Dare and Papadaki 2016; O'Neill 2007; Heinich and Pollak).

Correspondingly, the curator-as both the creator of context and the coordinator of the process that leads to an exhibition ${ }^{2}$ —needs to be aware of the medium that the artists use (whether this employs new technology or obsolete media) as much as of the work itself. Especially, when discussing the potential of historicizing of technology-reliant art via exhibitions, we need to realize that "[t]he history of technology and media sciences plays an equally important role [as art history] in this art's formation and reception" and that "new media art requires media literacy" (Paul 2008, p. 5). ${ }^{3}$

In this light, an effective way forward would be to think in terms of behaviours rather than the nature of its medium and its function; equally, towards a more process-based practice that centres around "temporary exhibitions" and "the specific context of their audiences" (Cook 2008, p. 29; Cook 2003; Greenberg et al. 1996). As will be explored later in this chapter, those behaviours could expand to include the dialogue between the works themselves in the exhibition space and the overall spatial synthesis in the creation of meaning. With increasing touring franchise 'productions' and temporary exhibitions that cater for their audiences, a more holistic approach towards creating context via exhibitions with a clear identity and works that can inform one another in the exhibition space could provide a new framework for viewing, historicizing, and documenting digital art.

As Graham and Cook (2010) have repeatedly (and justly) argued, and Steve Dietz has reverbed, new media (or digital, or technology-reliant) art is not merely about viewing but also about processes, interactivity and networks (Graham and Cook 2010, p. xiii). By extension, one could suggest that all types of technology-reliant works present characteristics that distinguish it from static art and thus create new types of environments where they can be exhibited. As such, the technology used constitutes a context around which the work is developed and serves as a vehicle for the communication of an idea; it is not to constitute the content of the work or to comment about questions surrounding technology. Furthermore, the understanding of a medium is also dependent on the cultural history

2 This point of the curator's role is also raised at various times in the published discussions of the BALTIC series, as well as in the-now defunct-CRUMB forum.

3 At the workshop 'Digital Audiovisual Preservation in Communities of Practice' (Presto Centre and Institut National de l'Audiovisuel, Paris, 4 December 2013), Pip Laurenson (Head of Collection Care Research, Tate) presented the challenges that arose when copying obsolete technologies (such as a Sony $\frac{1}{2}$ inch tape) onto new formats, in order to preserve the work and enable its future exhibiting. In the international declaration "Media Art needs global networked organisation and support", the pressing issue of major works that can no longer be shown or are disappearing is addressed (http://www.mediaarthistory.org/declaration, last accessed on 24 June 2019). The preservation of digital data is a fertile subject of research, although it expands beyond the scope of the present paper. However, it demonstrates that there is a history behind technology-bound pieces, as well as exhibiting limitations that both need to be known and acknowledged by curators. 
that each theorist emerges from. ${ }^{4}$ In this respect, curators need to remain clear at all times on the scope of the exhibition they organize. For this purpose, Christiane Paul takes, as a starting point, the need for curators to "know what type of exhibition they are putting together", whether this is "chronological, medium-based, or thematic", and to define where digital media plays the role of "a tool, a medium or a theme" (Paul 2003; quoted in Graham and Cook 2010, p. 5). ${ }^{5}$

\subsection{Display Issues in Exhibiting Technology-Reliant Works}

The particular characteristics that differentiate technology-reliant works from stable forms create a new set of rules for exhibition practices. Firstly, the notion of space is disrupted. The visitors may stop, stand and/or interact with a technology-reliant work, whereas, with a static object, they can view it whilst in (usually linear) movement within the exhibition space and proceed to the next work without stopping. In this context, the traits of the medium used to produce the work, together with its sheer volume, light and sound emission, and/or participatory nature, need to be taken into account when making curatorial decisions for the staging of the exhibition space. As an example of this, Rafael Lozano-Hemmer's The Year's Midnight (2011), presented at the Digital Revolution exhibition in London (discussed later on in the article), was a highly successful interactive piece (in terms of the number of visitors queuing to use it) which would have overshadowed all surrounding exhibits had there not been adequate curatorial consideration of the orchestration of said works in space (the piece was installed towards the corner of the exhibition pathway and did not face the incoming visitors).

Secondly, the light intensity of the image and/or the sound interact with the surrounding works and can complement or overshadow them, thus there are additional factors to be taken into account when organizing the install. In Videographies_-The Early Decades, a group exhibition on video art in Athens, ${ }^{6}$ Bruce Nauman's works were presented on cinematic screens hanging from the ceiling and placed one in front of the other (with a small gap of around one metre between them), so that the only way for one to see the work would be from a specific angle on the side of the screens. No sound was used (for a selection of works that all had sound) and the overall image from afar was this of one single light source. It was a presentation approach that worked well for the artist, since this arrangement created an impression of Nauman's general body of work, without reaching the extremes of either a traditional display (one screen projected on a wall next to the other) or of a synthesis that was impossible to watch (for instance, screens hanging too close to each other with no space in between for the physical presence of the viewer). This is an example for the work of a living artist who can agree to necessary arrangements or changes to the presentation of his work in different exhibition spaces. With most early technology-reliant artworks, though, one could deduce that this is not common practice and that there are strict sets of rules relating to their exhibiting.

Finally, taking into account the above premises, a new dynamic is created within the exhibition space; this situation requires a surplus of attention from the curator who now needs to visualize the ideal synthesis of exhibits in space in order to create a balanced orchestration of works that work well together and a virtual designated path for the visitors to follow, whilst also communicating the original purpose of the exhibition and its politics. An equally important factor in this process is the input from the artists as far as the display, technological requirements, and intention of their work are concerned. When researching museum and exhibition archives, I was impressed to witness the detail in which display specifications and technology requirements are recorded, and yet there are numerous examples when artists 'adapt' the work to spatial restrictions and the overall exhibition

4 “ $[. .$.$] thus Internet-founder Ted Nelson might see hypertext where art critic Jack Burnham sees sculpture or media theorist$ Lev Manovich sees database-driven video narrative" (Graham and Cook 2010, p. 1).

5 For a further analysis of the context/content dichotomy and subsequent curatorial judgements of quality, see (Dare and Papadaki 2016).

6 Videographies - The Early Decades (The Factory-National School of Fine Arts, National Museum of Contemporary Art, Athens, 13 July-31 December 2005). 
rationale. As briefly mentioned in the case of Nauman above, the artists' input in informing curators and museum professionals about preservation strategies and the possibilities of technological migration and/or upgrade of their work is of paramount importance when talking about the historicization of technology-reliant art via curatorial practice.

The three points above will be further discussed in the following section, but one can already see how a misjudged curatorial initiative in terms of the above traits could create an inaccurate historicization of the exhibited works or how, when successfully combining all the above, the exhibition can become a tool for effectively inscribing the works within the art history canon.

\subsection{Exhibiting Digital Histories}

Curators like to believe that the activity of curating art-which sometimes (but not necessarily) includes the collection of art-is the necessary precursor to the historicization of art. [... ] Yet what if instead of looking backwards-assuming those named things which are collected [... ] are the subject of art history-we look forwards, to how the early stages of curatorial activity (the finding, naming, and showing) inform what, from the wide world, is to become a possible subject for art history in the first place? (Cook 2014 in Graham 2014, p. 203)

It's all too easy to suggest that exhibitions have the potential to become 'historicizing' devices for art that do not fit into categories predetermined by a traditional art history canon. Cook acutely points out that art historians still use the same methodologies to 'assess' an artist or a work of art whilst, at the same time, the works themselves have evolved into entities that can no longer fit into these categories (Cook 2014, p. 204). Indeed, not only is there an issue in assessing and categorizing a technology-reliant work, but also one of naming and keeping up with the evolution of the work itself, technology, and terms used. As becomes evident in most institutional collections (Cook makes a point out of Gere (2004) research at the Tate), there are considerable gaps and/or shortages in having works of new media art in the collection.

Cook further suggests a new way forward via curatorial practice functioning towards the "interrupt[ion of] the formation of a canon" and the "reshap[ing of] art history in relation to these collections and object-oriented histories" (Cook 2014, p. 205). Looking at some recent exhibitions provides further insight on how this could be a legitimate possibility, while also exposing the dangers of applying an already hegemonic apparatus towards the appreciation and understanding (or not) of the work exhibited.

Digital Revolution (2014), presented as an "immersive exhibition of art, design, film, music and video games", 7 was first installed at Barbican Centre in London from 3 July to 14 September 2014, and then toured in Sweden, Greece, Turkey, China, and Germany (where it is currently shown). Following up on the idea of seeing contemporary curatorial practice as an ambassador and new method of creating art histories, the touring element is already an important factor in the exhibition in question. Spanning across a vast space across Barbican Centre, it professed to "look at the breadth of digital creativity in the 21 st century". 8 Not just that, one could easily argue, since its first section ("Digital Archaeology") mainly included works that were made from the 1970s until the end of the 20th century, thus providing a spherical vision of what was meant by 'digital' across the years. The exhibition was staged in an aesthetically balanced way, with works 'choreographed' across the vast surface where sound and projected colours often overlap between works (Figure 2). Apart from its major participants, entertainment value and Instagrammable qualities, it stood as an example of how a curatorial initiative can indeed write history across the globe in its own terms.

7 More information from the official link from Barbican Centre website: https://www.barbican.org.uk/hire/exhibition-hire-bie/ digital-revolution (last accessed on 24 June 2019).

8 Conrad Bodman, Guest Curator of Digital Revolution, on a clip promoting it ("Welcome to the Digital Revolution", link as above). 


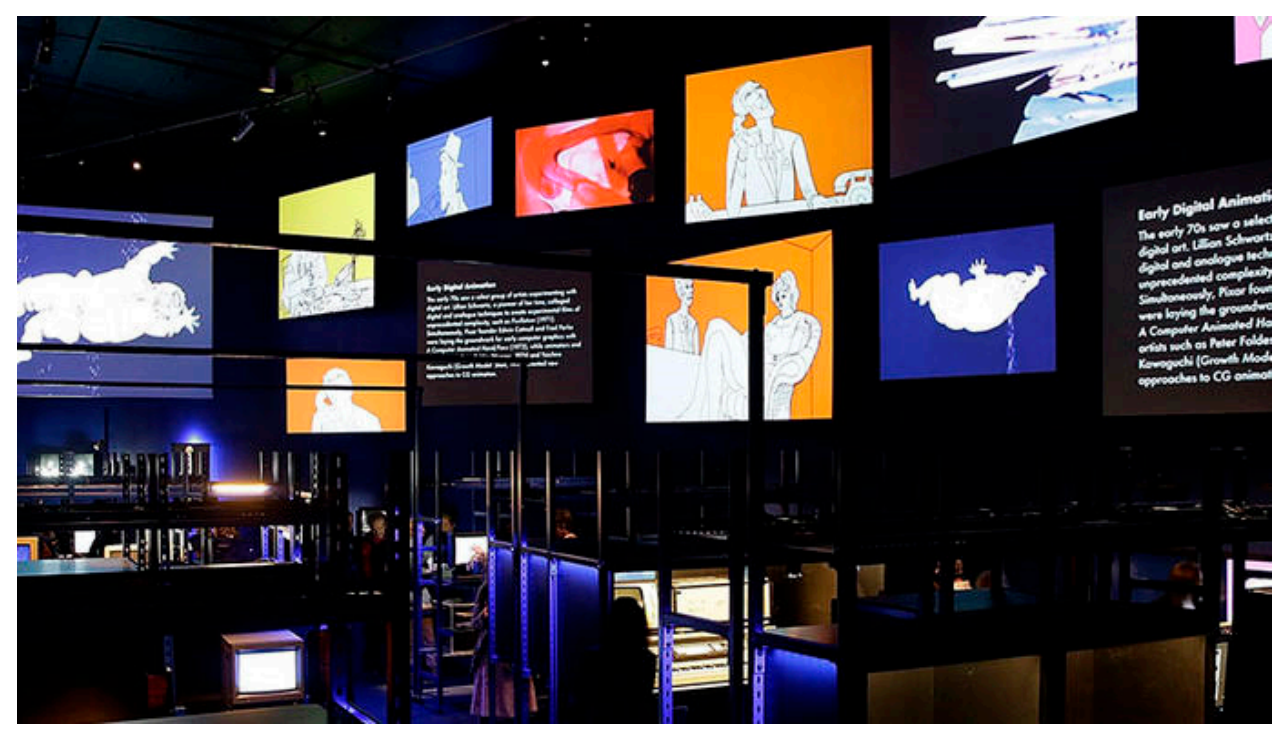

Figure 2. Digital Revolution (2014). Installation view (photo: courtesy of Barbican Centre).

Going back to the issue of judgements of taste and methodologies that are used to understand and historicize technology-reliant works of art, it makes sense to explore the layout of the exhibition as an example of different ways of thinking about exhibiting and how curatorial decisions have shaped the identity of said exhibition. The latter was installed at The Curve and so followed a semi-circular movement. It was split into six sections that helped create a mental map of the exhibits themselves, although one could equally suggest that some works worked well by being in proximity with others. The six 'units' were Digital Archaeology, We Create, Creative Spaces, Sound and Vision, State of Play, and Dev Art.

From a chronological point of view, it begins with Pong and Computer Animated Hand and Face (both 1972) and finishes with a number of works produced in the year of the exhibition opening (2014). As with most technology-reliant exhibitions spanning across decades of artistic production, the 'historical' pieces are placed separately. This is a choice that can produce tension, especially insofar as methodological criteria are concerned. However, if one takes into account the criteria mentioned in the previous section (space, installation components, synthesis of exhibits in space), the initiative is compatible with curatorial requirements of a choreographically balanced display, effectively communicated information and the artworks' respective histories.

In the case of Digital Revolution, the works from the first "Digital Archaeology" section could be seen as the 'predecessors' of what followed, from both a technological and aesthetic point of view; additionally, they created logical trajectories between the 'then' and the 'now', thus laying the foundations for a new historizing of the technology-reliant works. At the same time, thanks to the curatorial choice of creating a visual and sonic dialogue between the works, the exhibition functioned as a solid and consistent entity, rather than a series of isolated pieces. In this respect, the exhibition could be seen as employing both chronological, thematic and media-centred criteria when configuring both its narrative and display.

This was not the case with another major exhibition that also premiered in London two years later. Electronic Superhighway 2016-1966 opened at The Whitechapel Gallery in London in January 2016 professing to "show the impact of computer and internet technologies on artists from the mid-1960s to the present day". 9 Although the two exhibitions were roughly concerned with the same timescale, the curatorial decisions of the latter created a clear separation between the 'then' and the 'now'. The

9 Official exhibition link from the Whitechapel Gallery: https://www.whitechapelgallery.org/exhibitions/ electronicsuperhighway/ (last accessed on 24 June 2019). 
installation view, in this case, choreographed the 'contemporary' main section on the ground floor, with works dispersed in space that co-existed and at times visually informed one another. There were moments when the space felt too dense, according to some reviewers, with plenty of visitors who did not have enough passageway to either be informed on the exhibits themselves (by not being able to read the wall labels) or to even experience the work as it was meant to be seen. Although I didn't find the spatial synthesis itself problematic, I believe that part of the problem was the lack of narrative threads across the works. Compared to Digital Revolution, where exhibits were split into thematic units (even if this selection felt, at times, arbitrary) and the works seemed to nearly 'interact' with one another, the ground floor of the Electronic Superhighway 2016-1966 exhibition adopted a more 'liberal' curatorial approach that clearly did not work well with all visitors. Going back once more to the criteria of space, installation components, and synthesis of exhibits in space, visitors seemed to be confused from the lack of a clearly designated pathway to follow, and (although I would argue that there was a solid rationale behind the selection and display of works) no 'unifying thread' to keep all these works together in space (a fact that was overcome at Digital Revolution by creating the aforementioned visual and sonic dialogue between exhibits).

The main issue with the exhibition in question, however, in the context of inscribing technology-reliant art within a canonical curriculum via curatorial practice, has been the 'historic' install on the first floor (Figure 3). Apart from the linear placement of screens on pedestals, reminiscent of the chronological hang in a traditional museum setting, the works on show were visibly fewer than those on the ground floor. In his polemic against the methodology of the exhibition, Matthew Fuller exclaimed: "[a]s the show moves back through time with each of these phases, the inverse pyramid of art shown becomes smaller and the rooms get emptier as less work stands in for more art" (Fuller 2016). If one were to take this exhibition as an indicator of technology-reliant art production in the past fifty years, s/he would surely have a falsified perspective on both the quantity and typology of work created pre-1990s. Archival research at The Whitechapel Gallery reveals that there was, in fact, an accurate and solid rationale behind the selection of works. After having read the email exchanges between curators, museum professionals and artists, as well as having consulted the changing floor plans of the exhibition space, it becomes apparent that the final display choices were symptomatic of restrictions as far as the availability, loan of works and capacity to support obsolete technologies were concerned. With this in mind, it becomes all the more imperative to find an efficient way to historicize technology-reliant art via curatorial practice but also, to constantly question the (spatial) politics of curatorial choices.

Unfortunately, a scholar who has not physically visited the exhibitions cannot have a spherical view over the manner in which the works functioned in space or in relation to one another. Archival research usually offers a list of works, the email exchange between curators/organisers of the show (which is useful when attempting to understand the politics and logistics behind choices made) and a floor plan. In my personal experience as a researcher, and especially when attempting to visualize historic exhibitions focused on technology-reliant art, I have struggled to find any material that could give me an idea of the installation plan and, consequently, the way in which the works entered into dialogue with one another and created a narrative. Once more, the methodologies used to document an exhibition are obsolete and seem to have as a reference point the hangs or installations of static objects rather than a collection of works whose volume, sound, luminosity and interactivity have an effect on both the visitors and the co-exhibited works. It is ironic to think that technology has entered so drastically into the exhibition space but has yet to make an impact in the way that artists' work and exhibitions are documented. ${ }^{10}$ Consequently, an essential element for successfully using curatorial practice as a methodological tool for historicizing technology-reliant art would be to document a

10 At the same time, a quick YouTube or Google search reveals a plethora of home-made videos from exhibition spaces and exhibits, that are usually taken by visitors without permission and then uploaded online. 
detailed tour of the exhibition and keep an audiovisual archive where one can see not only the chosen placement of the works (on paper) but also have access to a spherical view of the show and the ways in which it worked as a whole. A key point in this process would be to constitute a network of participating institutions and online entities to set an agenda and key methodological guidelines in order to consistently and coherently record exhibitions. This would be a valuable tool not only for researchers but for the institutions themselves, as they would have an archive of curatorial processes and finalized outcomes for future use.

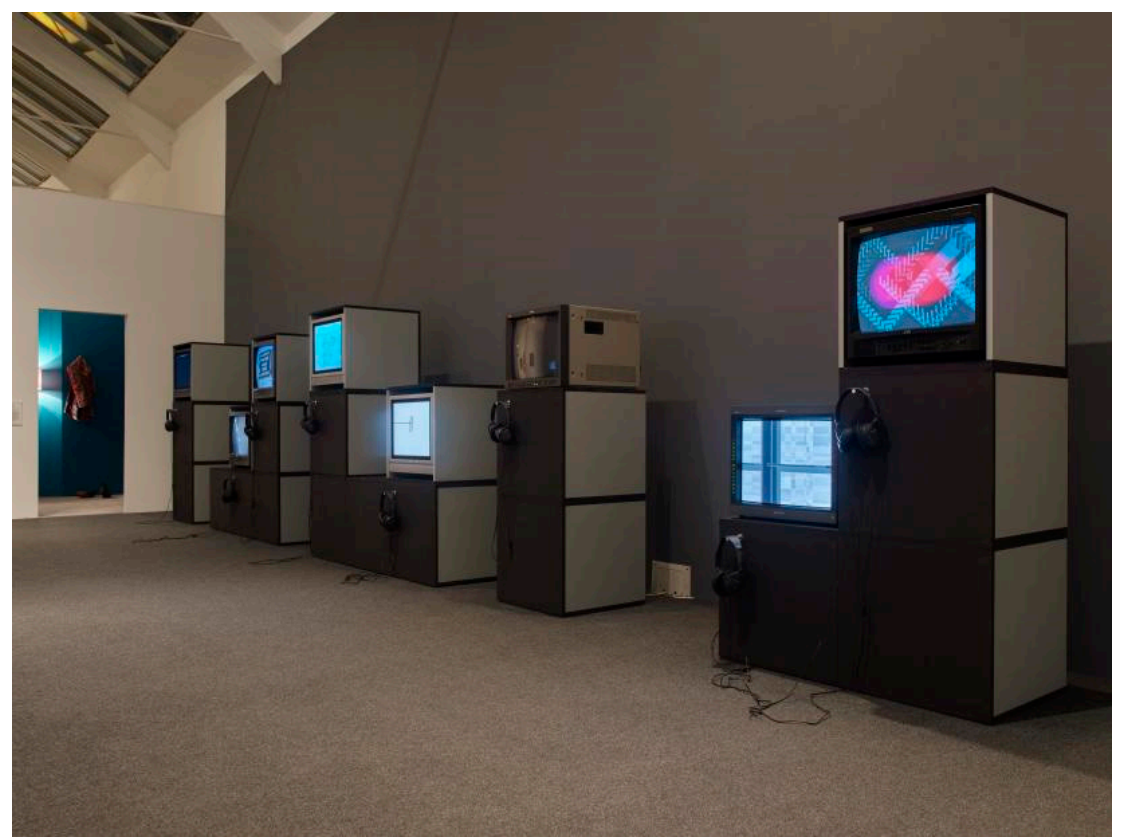

Figure 3. Electronic Superhighway 2016-1966 (2016). Installation view, first floor (photo: Whitechapel Gallery).

\subsection{Whose Histories?}

As I am writing this, an intense discussion is developing in the "New-Media-Curating" mailing list on the topic of VR/immersive media and the subsequent appreciation of their qualities. Originally starting from a post titled "Curating VR art" (17 June 2019) that reviewed the VRHAM festival in Hamburg, it opened its scope to include immersive installations. TeamLab's What a Loving and Beautiful World [2011] sparkled the conversation, as it is currently exhibited in AI: More than Human exhibition at Barbican Centre (London), and was in turn, characterized as "superficially pretty and silly" and "decorative and trivial". A great part of the criticism came from the authors failing to interact with the work as was originally intended; this didn't reflect my personal experience, as the interactive element worked fine when I visited the space, but it surely creates a distinctively different perception of the piece when this central part of its presentation does not function correctly. In any case, the discussion in question is particularly symptomatic of issues that arise when talking about technology-reliant art and subject-matters which need to be renegotiated in the framework of a new method of experiencing (and assessing) the former. There are two main themes to be addressed here:

1. The aesthetics of the piece and the context within which it was created. As mentioned earlier, the 'naïve' aesthetics of the work was one of the first points of criticism. However, amongst the arguments in defence of the art collective was the realisation that their work is "deeply embedded in aesthetics of Japanese art and culture which may require some translation" (Christiane Paul's response to the email thread). One might as well see this as a 'culture clash'; the UK traditionally separated art from design, whereas in Japan the two are usually indistinguishable (Beryl Graham's response, with a reference to Gere (2004) Tate paper “New Media Art and the Gallery in the Digital 
Age"). Furthermore, TeamLab integrate numerous references from Japanese history and culture in their work which, however, cannot be easily understood from a Western-audience perspective. The first work that one witnesses when visiting their headquarters in Tokyo is a screen with an animated story showing how agricultural work takes place in the rice fields throughout the year. Informative and yet entertaining, one of the first things they mention is that they want to communicate their ideas without excluding the 'fun factor' or becoming overtly educational in their nature. Equally, a funny-looking frog that appears in many of their interactive creations is, in fact, Choju-giga, a central character from one of the oldest picture scrolls in Japanese history, dating back to the 12 th century. ${ }^{11}$ My Japanese acquaintances could automatically read all those references, aesthetics of the image, and humbleness of the spectacle itself, whereas I had to ask endless questions only to begin to comprehend the ways in which they saw their work and managed to combine commercial and artistic projects. The above logic certainly informs their practice, which, in turn, generates issues relating to the context and receivability of non-Western or non-canonical art that can be applied to numerous contemporary cases of technology-reliant art, and the subsequent questioning of the tools we have, as researchers and/or exhibition visitors, to decode the messages conveyed.

2. Curatorial choices that placed What a Loving and Beautiful World outside the main exhibition space of the AI: More than Human exhibition. Although other works were exhibited outside The Curve (where the largest part of the exhibition was shown), they were all on the same floor level. However, one needed to change floors and enter a separate space to experience the TeamLab piece (Figure 4). Understandably, this could only be shown in an isolated space with no other visual or sonic interference but its placement in a separate location still conceptually excluded it from the rest of the exhibition. Institutional logistics aside, the politics of space play an essential role in the understanding and historicization of a technology-reliant work.

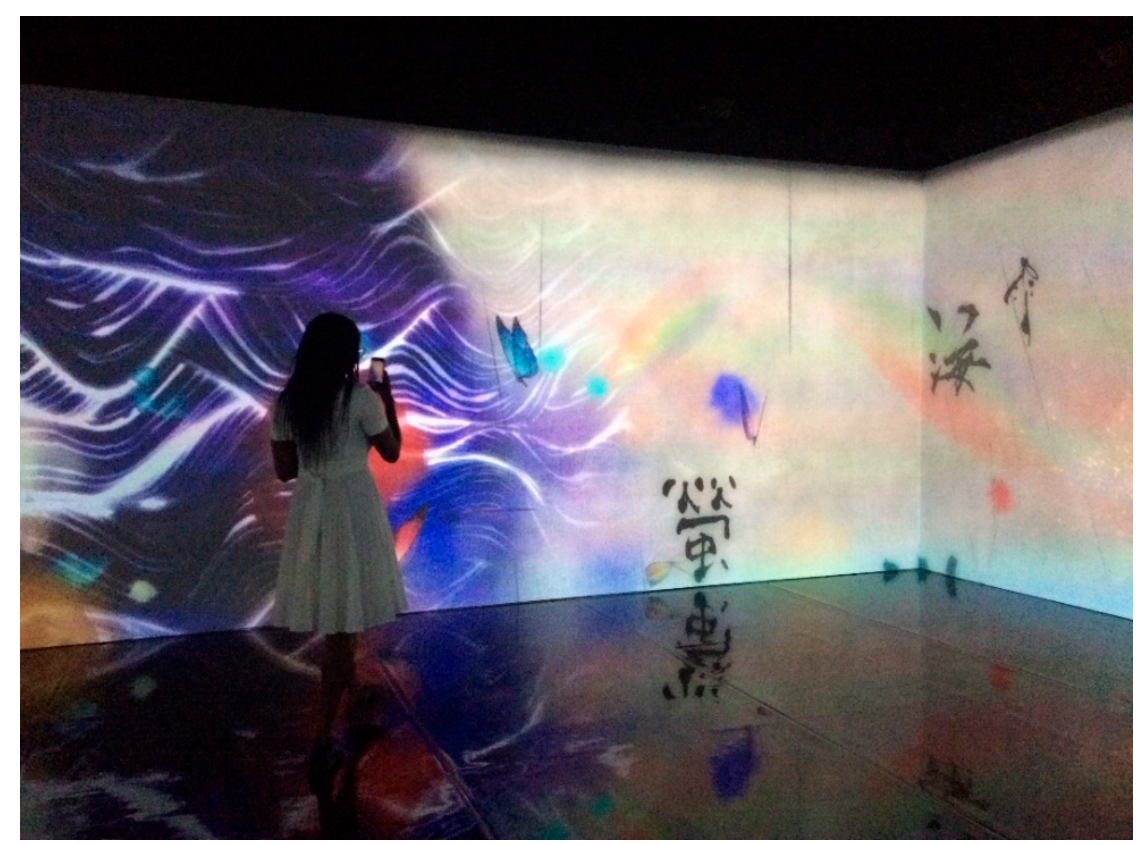

Figure 4. TeamLab. What a Loving and Beautiful World (2011). Installation view-Barbican Centre 2019 (author's photo).

11 Interview with TeamLab in their headquarters in Tokyo, June 2018. 
Even within an exhibition framework, the factors that need to be taken into account when experiencing the works go beyond the mere conceptual link with the scope of the exhibition itself and its institutional context.

Discussions in mailing lists are good in offering an insight into those experiences, thoughts, opinions, and anecdotes that would not, under normal circumstances, be found in scholarly texts. In this case, it becomes all the more evident that indeed, the methodologies that are often employed in order to assess a technology-reliant work of art are still inscribed within the traditional art history canon.

\section{Conclusions/Towards a Holistic Exhibition Regime}

Based on theoretical research and selected examples from recent exhibitions, this paper presented a pattern of curating technology-reliant works and suggested a spherical approach towards exhibition viewing and documentation, arguing that both are of paramount importance for the historicization and evaluation of technology-reliant art within an exhibition space. Further research could be conducted towards a documentation model that captures the essential elements of an exhibition and introduces a new research methodology for adequately historicizing technology-reliant art, especially works whose qualities per se make them difficult to witness and understand out of context or outside the exhibition framework.

While it is important to acknowledge the vital role of major institutions and blockbuster exhibitions in a potential shift towards a more inclusive pattern of historicizing, assessing, and documenting technology-reliant art, one also needs to think about works that happen outside the aforementioned institutional space. Numerous examples of ephemeral art, happenings, and large-scale interactive public events can neither be adequately described nor experienced anew in an identical manner. Their exploration is beyond the scope of the present paper, but the same methodology of documentation could be applied in order to achieve an all-inclusive historicization of the works in question.

In fact, documentation is of paramount importance for the historicization and evaluation of technology-reliant art within an exhibition space. A list of works and floor plan surely cannot reproduce either the interaction between works or the difference in scale and overall synthesis of the exhibition space. The more curatorial choices create meaning via the juxtaposition of different qualities of works (colour, sound, size, etc.), the more it becomes imperative for these choices to be accessible to future scholars.

Funding: This research received no external funding.

Acknowledgments: Nayia Yiakoumaki (Curator: Archive Gallery, Whitechapel Gallery, London), Dor Duncan (Archivist, Whitechapel Gallery, London), Sharon Kent (Exhibitions Department and Private View Coordinator, The Barbican, London), and Marta Faustino (The Barbican, London) for their help and support in accessing the exhibition archives; TeamLab (TeamLab headquarters, Tokyo) for a most enjoyable interview and guided tour of their offices and workspace.

Conflicts of Interest: The author declares no conflict of interest.

\section{References}

Cook, Sarah. 2003. Towards a Theory of the Practice of Curating New Media Art. In Beyond the Box-Diverging Curatorial Practices. Edited by Melanie Townsend. Banff: Banff Centre Press.

Cook, Sarah. 2014. Murky Categorisation and Bearing Witness: The Varied Processes of the Historicization of New Media Art. In New Collecting: Exhibiting and Audiences after New Media Art. Edited by Beryl Graham. Farnham: Ashgate, pp. 203-19.

Cook, Sarah. 2008. Immateriality and its discontents: models of curating new media art. In New Media in the Whiet Cube and Beyond: Curatorial Models for Digital Art. Edited by Christiane Paul. Berkeley and London: University of California Press.

Dare, Eleanor, and Elena Papadaki. 2016. Bare Nothingness: Situated objects in embodied artists' systems. In Experimental Multimedia Systems for Interactivity and Strategic Innovation. Edited by Ioannis Deliyannis and Christine Banou. Hershey: IGI Global, pp. 16-48. 
Fuller, Matthew. 2016. Eleven Pro-Tips for Art Plus Internet. Available online: http://www.metamute.org/editorial/ articles/eleven-pro-tips-art-plus-internet (accessed on 24 June 2019).

Gere, Charlie. 2004. New Media Art and the Gallery in the Digital Age. Tate Papers. Available online: https://www.tate.org.uk/research/publications/tate-papers/02/new-media-art-and-the-gallery-inthe-digital-age (accessed on 24 June 2019).

Graham, Beryl. 2014. New Collecting: Exhibiting and Audiences after New Media Art. Edited by Beryl Graham. Farnham: Ashgate.

Graham, Beryl, and Sarah Cook. 2010. Rethinking Curating: Art after New Media. Cambridge and London: MIT Press.

Grau, Oliver. 2003. Virtual Art_-From Illusion to Immersion. London and Cambridge: MIT Press.

Greenberg, Reesa, Bruce Ferguson, and Sandy Naime, eds. 1996. Thinking about Exhibitions. London: Routledge.

Heinich, Nathalie, and Michael Pollak. From Museum Curator to Exhibition Auteur: inventing a singular position. In Thinking about Exhibitions. Edited by Reesa Greenberg, Bruce Ferguson and Sandy Nairne. London: Routledge.

Kholeif, Omar. 2018. Goodbye, World! Looking at Art in the Digital Age. Berlin: Sternberg Press.

Meigh-Andrews, Chris. 2006. A History of Video Art: The Development of Form and Function. Oxford and New York: Berg.

Mondloch, Kate. 2010. Screens: Viewing Media Installation Art. Minneapolis: University of Minnesota Press.

O'Neill, Paul. 2007. The Curatorial Turn: From Practice to Discourse. In Issues in Curating Contemporary Art and Performance. Edited by Judith Rugg and Michèle Sedgwick. Chicago and Bristol: Intellect, pp. 13-28.

Papadaki, Elena. Curating Screens: Art, Performance, and Public Spaces. Ph.D. Thesis, Goldsmiths, University of London, London, UK.

Paul, Christiane. 2008. New Media in the White Cube and Beyond. London, Berkeley and Los Angeles: University of California Press.

Paul, Christiane. 2003. Digital Art. London: Thames \& Hudson.

Shanken, Edward A. 2010. Contemporary Art and New Media: Toward a Hybrid Discourse? Available online: https://artexetra.files.wordpress.com/2009/02/shanken-hybrid-discourse-draft-0-2.pdf (accessed on 10 July 2019).

Trodd, Tamara. 2011. Screen/Space-The Projected Image in Contemporary Art. Manchester: Manchester University Press.

(C) 2019 by the author. Licensee MDPI, Basel, Switzerland. This article is an open access article distributed under the terms and conditions of the Creative Commons Attribution (CC BY) license (http://creativecommons.org/licenses/by/4.0/). 